\title{
Approaches to Inclusive Education and Implications for Curriculum Theory and Practice
}

\author{
Mercy M. Mugambi \\ School of Education, University of Nairobi, Kenya \\ *Corresponding Author: Mercy M. Mugambi, School of Education, University of Nairobi, Kenya
}

\begin{abstract}
Education is a fundamental human right as well as an instrument for economic growth and human development. Education is valued because it contributes to national development through the provision of human resource that helps to stimulate productivity and eliminate poverty, disease and ignorance. The World Declaration on Education for All adopted in Jomtein, Thailand (1990) set out the vision on universalizing access to education for all topromote equity. Inclusive education aims to strengthen the capacity of the education system to reach out to all children. Learning should be based on the clear understanding that learners are individuals with diverse characteristics and backgrounds, and the strategies to improve quality should therefore draw on learners' knowledge and strength. Many Acts originating from the 1948 Universal Declaration of Human Rights have been documented to support inclusive education. Despite the emphasis on inclusive education, many challenges face its implementation: many curricula in learning institutions are still built around a model of a 'traditional' student which creates challenges for many of different types of learners; studies show that teachers do not feel prepared to undertake responsibility of an inclusive classroom and most times, teachers are not sure what to expect socially.; learning environment fail to support nature of different learners and un authentic assessment of achievement of learning outcomes. This paper presents the human right based and multicultural approaches to inclusive education and their implications for curriculum theory and practice in relation to differentiated curriculum content, instructional process, differentiated assessment, reorienting teacher education and involvement of parents and community.
\end{abstract}

Keywords: Approaches to inclusive education, Curriculum theory and practice, Curriculum Implementation, Inclusive Education

\section{INTRODUCTION}

Worldwide, there has been emphasis on the need to extend access to education to all. This has been verified through a number of international conventions which include: the Salamanca statement on special needs education, UNESCO, 1994, the UN convention on the Right of the Child, 1989, and the UN international convention on the Right of the Persons with Disabilities (2000). Education is understood as a tool that can be used to reduce poverty, to improve the lives of individuals and groups, and to transform societies (Grubb and Lazerson, 2004). Providing an inclusive education to all is necessary because it is linked to human, economic, and social development goals. Failure of any education system to provide an education for all children not only leads to an educational underclass, but also a social and economic underclass which has serious consequences for society now and in the future. Development of policies that support inclusive education at all levels of education is essential as a way of promoting learning and participation of all children in education.

The global emphasis on 'knowledge economy' has necessitated competitive reforms in education to increase efficiency of the school system and also to comply with the market place principles in education (Ball, 2006). Might these disadvantage learners with some learning difficulties? To ensure that no child is disadvantaged, 'main stream' reform legislation has been enacted by many countries to develop their special education system or to encourage greater inclusion of children considered to have disabilities or learning difficulties. Such a policy has implications on the role of the teacher and learning institutions, the curriculum and teacher education programmes. Dealing with differences and diversity of learners continues to one of the biggest challenges faced by learning institutions across many countries (European Agency on the Development of Special Education, 2006). Some of the challenges arise from inflexible or irrelevant curriculum, didactic teaching methods, and inappropriate 
approaches to assessment and examination, poor preparation of teachers and limited teacher support system.

Seed (2006), notes that successful teaching of children with individual differences requires that they are grouped homogeneously so that special pedagogical approaches can be deployed by the teachers who have been trained to use them so that the system encourages participation for all learners. Evans and Lunt (2012) observe that the implementation of inclusive education policies has been uneven globally. Many reasons are associated with these disparities; limited funding, and resources, competing polices that stress the achievement of set standards among others. Additionally, it has been suggested that one of the greatest barriers to the development of inclusion is because teachers do not have the required competencies (knowledge, skills and attitudes) to implement policies on inclusive education.

Social justice and inclusion are highly important in today's society and are sought after in the twenty first century of education to allow every child to flourish in their learning in and have their talents nurtured and developed (Commission for Social Justice, 1994). Social justice in education can only be delivered by inclusive schools and teachers (Dyson, 1999). Social justice implies a sense of fairness which ensures social circumstances are not regarded as barriers to achievement (Field etal, 2007).Failure to acknowledge this becomes an obstruct to accessibility of learning making it exclusive to some children. Individual differences are key influencing factors in deciding what and how to provide for individuals in the classroom and some learners may require additional support resource to achieve. An education system embracing social justice is one which recognizes the significance of and strives to enhance not only learners'intellectual growth but also their overall wellbeing (Reay, 2014).Inclusive education is on the global agenda to attract the involvement and collaboration of all stakeholders.

\section{CONCEPT OF INCLUSIVE EDUCATION}

Inclusive education is the process of strengthening the capacity of education system to reach out to all learners as a strategy to achieve education for all. The world Declaration on Education for All adopted in Jomtien Thailand (1990), set out as an overall vision: Universalizing access to education for all children, youth, adults and promoting equality. This means being proactive in identifying the barriers that may be countered in accessing educational opportunities and identifying the resources needed to overcome these barriers. Inclusive moves emphasis away from pupils for whom curriculum is modified toward the process of responding to all pupils, acknowledging that any child could have additional support needs at any given time. More impetus for inclusive education was given at the world conference on Special needs education (SNE) on access and quality held in Salamanca, Spain June 1994. More than 300 participants representing 92 governments and 25 international organizations considered the fundamental policy shifts required to promote the approach of inclusive education, therebyenabling schools to serve all children, particularly those with special education needs. Each child should be included in the main stream schooling without any exclusion due to perceived differences or support needs. An inclusive education system can only be created if ordinary schools become more inclusive, that is, if they become better at educating all children in their communities. The Salamanca conference proclaimed that regular schools with an inclusion orientation are the most effective means of combating discriminatory attitudes, creating welcoming communities, building an inclusive society and achieving education for all.

Brooth (1998) views inclusive education as a process of 'increasing the participation of students in the culture and curricula of mainstream school and communities'. Bailey (1998) talks of inclusion as"being in an ordinary school with other students, following the same curriculum at the same time, in the same classroom, with the full acceptance of all, and in a way which makes the students feel no different from other students". Inclusive education looks at both the rights of learner and how education systems can be transformed to respond to the diverse groups of learners. Studies by Pijl et al (1997) show that attitude of teachers towards educating learners with special needs is very important if a school is to be inclusive. If main stream teachers do not take responsibility for the learning needs of those with special needs as an integral part of their job, they will cause segregation in learning to occur in schools thus fostering stereotypes. Inclusion is about the child's right to participate as fully as possible in school activities and the school's duty to accept and accommodate the child's right (Thomas and Vaughan, 2005). Inclusive education requires that a mainstream school 
considers all learners in its area as fully belonging to the school and all of its varied activities. Every child has the same right to access education.

Inclusive education is based on the fundamental human rights. Education is a fundamental human right, as enshrined in the Universal Declaration of Human Rights (United Nations, 1998). Children with or without disabilities have the same rights to educational opportunities under the United Nations Convention on the Rights of the child. According to Doyson et al (2004); Boothand Ainscow (2000) inclusion in learning institutions involves:

a. Valuing all learners equally.

b. Increasing the participation of learners.

c. Acknowledging the right of learners to an education.

d. Reducing exclusion of learners from their culture, curricula and communities of local learning institutions.

e. Restructuring policies, practices and cultures in schools so that they respond to the diversity of learners.

f. Reducing barriers to learning and participation for all learners, not only those with impairment or those that are categorized as 'having special learning needs'.

g. Ensuring adequate teacher preparation.

h. Enhancing support services to learners rather than moving them to other services.

i. Providing an appropriate physical environment.

j. Developing a culture of acceptance by removing barriers to educational outcomes.

k. Removing discrimination.

1. Providing adequate resources.

m. Focusing on collaborative role of parents.

n. Fostering mutually sustaining relationship between schools and communities.

o. Reducing class size based on the severity of learners needs.

p. Using of authentic assessment approaches as opposed to the tradition education where learners are assessed by standardized examinations.

q. Professional skill development in areas of cooperative learning, peer tutoring and adaptive curriculum.

Inclusion recognizes the right of all learners including those with learning difficulties. Inclusion therefore means that students with special needs met in a mainstream education system that embraces a wide diversity of learners. Inclusion should thus be seen as a process of addressing and responding to the diverse needs of all children, youth, and adults through increasing participation in learning cultures, and communities, and reducing and eliminating exclusion within and from education. It involves changes and modifications in content, approaches, structures and strategies with a common vision that covers all children in the regular school system. Article 24 of the convention on the Rights of Persons with Disabilities, adopted in 2006 advocate for inclusive education which forms the bases for development of inclusive education policies and approaches. Barriers to inclusion can be reduced through active collaboration between pool makers, education personnel and other stakeholders including the active involvement of members of the local community, such as political and political leaders, local education officials and media.

The Dakar Frame work of Action clearly paves the way for inclusive education as one of the main strategies to address the challenge of marginalization and exclusion in response to the fundamental principle of AFA, namely that all children, youth and adults should have an opportunity to learn. Education must be viewed as a facilitator in everyone's development and functionality, regardless of barriers of any kind, physical or otherwise. Inclusive education supports and promotes a broader vision of society where all people are included, regardless of their impairment. 
A range of international human rights instruments have long established the right to education for all. The Universal Declaration of Human Rights (1948) firmly established education as a human right for all people. The United Nations Educational, Scientific and Cultural Organization (UNESCO) Convention against Discrimination in Education (1960), the first specific instrument concerned with the right to education, is based on the principles of nondiscrimination and equal opportunities in education. The Convention on the Rights of the Child (1990), the most widely ratified international human rights treaty, highlights the need for governments to ensure access to education for disabled children. The Salamanca Statement (1994) stresses the importance of inclusive education, calling on governments to 'give the highestpolicy and budgetary priority to enable them to include all children regardless of individual differences or difficulties' and to 'adopt as a matter of law or policy the principle of inclusive education, enrolling all children in mainstream schools, unless there are compelling reasons for doing otherwise'.This commitment to inclusive education became a legal obligation through Article 24 of the 2006 Convention on the Rights of Persons with Disabilities (CRPD), which reaffirms the right of disabled children to quality education and committed governments to ensure that "persons with disabilities can access an inclusive, quality and free primary education and secondary education on an equal basis with others in the communities in which they live'. Article 32 places an obligation on donor governments to make their support 'inclusive of and accessible to persons with disabilities'.

\section{Policy GUidelines ON INCLUSION IN EDUCATION}

Children with disabilities are still combating obvious educational exclusion. Working children, those belonging to indigenous groups, rural populations and linguistic minorities, nomadic children and those affected by HIV and AIDS are other venerable groups. It is of crucial importance that all children and young people have access to education, it is equally important that they are able to take full part in school life and achieve desired outcome from their education experience. While subject based academic performance is often used as an indicator of learning outcomes,' learning achievement" needs to be conceived as the acquisition of values, attitudes, knowledge and skills required to meet the challenges of contemporary societies. Promoting inclusion means encouraging positive attitudes and improving educational and social frameworks to cope with the new demands in educational structures and governance. It also involves improving inputs, processes and environment to foster learning, both at the level of the learner in his/her learning environment and at the system level to support the entire learning experience (UNESCO, 2007).Some important steps in policy promotion of inclusive education should include:

a) Conducting a local situation analysis on the scope of the issue, available resources and their utilization to support inclusion and inclusive education.

b) Mobilization of opinion on the right of education for everybody.

c) Building of consensus around the concepts of inclusive and quality education.

d) Making legislation reforms to support inclusive education in line with international conventions, declarations and recommendations.

e) Supporting local capacity building to promote development towards inclusive education.

f) Developing ways of assessing the impact of inclusive and quality education.

g) Developing school and community based mechanisms to identify children not in school and find ways to help them enter school and remain there.

h) Helping teachers to understand their role in inclusive education and that inclusion of diversity in education is an opportunity and not a problem.

i) Eliminating legislative or constitutional barriers to disabled people being included in the mainstream education system.

j) Ensuring that education policies and strategies promote inclusive learning environments.

k) Initiating and facilitating national consultative processes, informed by international research, experience and standards, to develop national standards for inclusive education and for enhancing the quality of learning outcomes. 
1) Developing strategies which increase community and family involvement in school management committees and education offices, including encouraging inputs into budget priorities and the tracking of expenditure.

m) Facilitating participation, develop awareness programmes for the parents of disabled children, and the children themselves, about their rights.

n) Providing pre-service and in-service training to teachers so that they can identify and respond to the needs of each child (for example, using peer-support and activity-based approaches) and promote diversity in the classroom. Ensure there is adequate support and expertise in skills such as Braille literacy, and provide for the training and employment of disabled teachers.

o) Training and orienting educational administrators, school leadership, and support staff, as well as communities, on the rights of disabled children to education and on good practice in inclusion.

Inclusive education is thus a systematic change at all levels; principals, teachers, learners, school communities, policy makers, decision makers, families, and society at large. Access to mainstream education alone is not enough. Participation means that all learners are engaged in learning activities that are meaningful for them. The promotion of positive attitudes in education is crucial for widening participation. Parental and teacher attitudes towards the education of learners with a wide range of needs appear to be largely determined by personal experiences; this fact needs to be recognized and strategies and resources implemented to address attitudinal factors. Effective strategies to promote positive attitudes include:

a) Ensuring all teachers are trained and feel able to assume responsibility for all learners, whatever their individual needs.

b) Supporting the participation of learners and their parents in educational decision-making. This includes involving learner's indecisions about their own learning and supporting parents to make informed choices for their (younger) children. At the level of an individual learner's educational career, the following aspects appear to make a significant contribution to achieving the goal of widening participation.

c) A view of learning as process - not content based - and a main goal for all learners being the development of learning to learn skills, not just subject knowledge.

d) Developing personalized learning approaches for all learners, where the learner sets, records and reviews their own learning goals in collaboration with their teachers and families and is helped to develop a structured way of learning independently in order to take control of their own learning.

e) The development of an Individual Education Plan (IEP) or similar individualized teaching programme, for some learners (possibly with more complex learning needs) who may require a more focused approach for their learning. IEPs should be developed to maximize learners' independence and involvement in goal setting and also collaboration with parents and families.

f) An approach to learning that aims to meet the diverse needs of all learners without labeling/categorizing is consistent with inclusive principles and requires the implementation of educational strategies and approaches that will be beneficial to all learners.

g) Co-operative teaching where teachers take a team approach involving learners themselves, parents, peers, other school teachers and support staff, as well as multi-disciplinary team members as appropriate.

h) Co-operative learning where learners help each other in different ways - including peer tutoring within flexible and well-thought out learner groupings.

i) Collaborative problem solving involving systematic approaches to positive classroom management.

j) Heterogeneous grouping of learners and a differentiated approach to dealing with a diversity of learners' needs in the classroom. Such an approach involves structured goal setting, reviewing and recording, alternative routes for learning, flexible instruction and different ways of grouping for all learners.

k) Effective teaching approaches based on targeted goals, alternative routes for learning, flexible instruction and the use of clear feedback to learners. 
1) Teacher assessment that supports learning and does not label or lead to negative consequences for learners. Assessment should take a holistic/ecological view that considers academic, behavioural, social and emotional aspects of learning and clearly informs next steps in the learning process.

Strategies for widening participation within mainstream classrooms cannot be implemented in isolation from the context of the wider school and home situation. In order to increase educational opportunities for all learners, a number of inter-connected factors must be in place to support the work of individual teachers.

\section{APPROACHES TO INCLUSIVE EDUCATION}

This section focuses on two approaches: the Human Right Based approach to inclusive education and the Multicultural Approach.

\subsection{Human Right Based Approach}

Many world governments have ratified the Convention on the Rights of the Child (CRC) a holistic human rights treaty addressing the social, economic, cultural, civic, and political and protection rights of children. It emphasizes both the right to education on basis of equality of opportunity and the broad aims of education in terms of promoting the fullest possible development of the child. Article 2 of CRC gives governments an obligation to assure the realization of all rights to every child without discrimination, including on the grounds of disability. Additionally Article 23 of CRC specially addresses the right of children with disabilities to assistance to ensure that they are able to access education in a manner that promotes their social inclusion. The committee on Childs rights identified four rights which must be understood as general principles to be applied in the realization of all other rights:

a) Nondiscrimination.

b) Best interest of the child.

c) Optimum development of the child.

d) The right of the child to be heard and taken seriously in accordance with age and maturity.

Article 24 of the 2006 Convention on the Rights of Persons with Disabilities (CRPD), which reaffirms the right of disabled children to quality education and committed governments to ensure that 'persons with disabilities can access an inclusive, quality and free primary education and secondary education on an equal basis with others in the communities in which they live'. Article 32 places an obligation on donor governments to make their support 'inclusive of and accessible to persons with disabilities'.

According to UNESCO (2007), several principles underpin a right based approach to education:

1. Universality and inalienability - human rights are universal and an entitlement of all people everywhere in the world.

2. Indivisibility-human rights whether civil, cultural, economic, political or social are inherent to the dignity of every person.

3. Interdependent and interrelatedness- the realization of the rights often depends on wholly or in part on the realization of others.

4. Equality and non-discrimination- all individuals are equal as human beings and by virtue of the inherent dignity of each person are entitled to their rights without discrimination of any kind.

5. Participation and inclusion- every person and all people are entitled to active, free and meaningful participation in contribution to and enjoyment of civil, economic, social, cultural and political development.

6. Empowerment- this is the process through which people's capabilities to demand and use their human rights grow. The goal is to give people the power and capabilities to claim their rights, in order to change their own lives and improve their communities.

7. Accountability and respect for the rule of the law- a right based approach seeks to raise levels of accountability in the development process by identifying 'rights holders' and corresponding 'duty bearers' and to enhance the capacities to those duty bearers to meet their obligation. 
Systems of education must therefore strive to fulfill the right to education, respect the right to education, and protect the right to education.

\subsection{Multicultural Approach}

Multicultural education describes a system of instruction that attempts to foster cultural pluralism and acknowledges the differences between races and cultures. It addresses the educational needs of a society that contains more than one set of traditions that is a mixture of many cultures. The goal of multicultural education is to help students understand and appreciate cultural differences and similarities and to recognize the accomplishments of diverse ethnic, racial, and socioeconomic groups. It is a practice that hopes to transform the ways in which students are instructed by giving equal attention to the contributions of all the groups in a society. Multicultural education aims to eliminate prejudice, racism and all forms of oppression. To do this, "it is imperative that multicultural educators give voice and substance to struggles against oppression and develop the vision and the power of our future citizens to forge a more just society." According to Sleeter andGrant(2008) Multicultural education addresses issues of white privilege, challenges the status quo, and compels students and teachers to identify their own biases. It increases awareness and understanding of racism, how it has shaped our society in the past and the manifestations of racism, classism and oppression in the contemporary world.

\subsection{The Dimensions of Multicultural Education}

According to Bank (1998), there are five dimensions of multicultural education:

a) Content integration which deals with the extent to which teachers use examples and content from a variety of cultures and groups to illustrate key concepts, generalizations, and issues within their subject areas or disciplines.

b) The knowledge construction process which describes how teachers help students to understand, investigate, and determine how the biases, frames of reference, and perspectives within a discipline influence the ways in which knowledge is constructed within it (Banks, 1998). Students also learn how to build knowledge themselves in this dimension.

c) Prejudice reductionwhich describes lessons and activities used by teachers to help students to develop positive attitudes toward different racial, ethnic, and cultural groups. Research indicates that children come to school with many negative attitudes toward and misconceptions about different racial and ethnic groups (Phinney \& Rotheram, 1987). Research also indicates that lessons, units, and teaching materials that include content about different racial and ethnic groups can help students to develop more positive intergroup attitudes if certain conditions exist in the teaching situation (Banks, 1998). These conditions include positive images of the ethnic groups in the materials and the use of multiethnic materials in a consistent and sequential way.

d) Equity pedagogy exists when teachers modify their teaching in ways that will facilitate the academic achievement of students from diverse racial, cultural, and social-class groups (Banks \& Banks, 1995). Research indicates that the academic achievement of African American and Mexican American students is increased when cooperative teaching activities and strategies, rather than competitive ones, are used in instruction. Cooperative learning activities also help all students, including middle-class White students, to develop more positive racial attitudes. However, to attain these positive outcomes, cooperative learning activities must have several important characteristics. The students from different racial and ethnic groups must feel that they have equal status in intergroup interactions, teachers and administrators must value and support cross-racial interactions, and students from different racial groups must work together in teams to pursue common goals.

e) An empowering school culture and social structure is created when the culture and organization of the school are transformed in ways that enable students from diverse racial, ethnic, and gender groups to experience equality and equal status. The implementation of this dimension requires that the total environment of the school be reformed, including the attitudes, beliefs, and action of teachers and administrators, the curriculum and course of study, assessment and testing procedures, and the styles and strategies used by teachers. 
To implement multicultural education effectively, teachers and administrators must attend to each of these dimensions of multicultural education. They should use content from diverse groups when teaching concepts and skills, help students to understand how knowledge in the various disciplines is constructed, help students to develop positive intergroup attitudes and behaviors, and modify their teaching strategies so that students from different racial, cultural, and social-class groups will experience equal educational opportunities. The total environment and culture of the school must also be transformed so that students from diverse ethnic and cultural groups will experience equal status in the culture and life of the school.

Multicultural education must create a safe place for all learners helping to reduce feelings of alienation among learners from certain groups, mitigate violence and bullying and counter radicalization of youth. Each learner must feel an equal participant and stakeholder in the enterprise of education. No one should feel abandoned, stranded, alienated or excluded. Multicultural education must deal with cultural differences rather than mare ethno cultural diversity. Human behinds are different from each other in different ways and this does not translate into deficiency or deviance when they differ from a tradition norm. It simply means they are different, but also that they have a right to be different. The aim of multicultural education is to empower all students with an ethical and democratic vision of society within which they can make a variety of contribution appropriate to their talents, needs, and aspirations.

\subsection{What are the goals of Multicultural education?}

According to Hanley (2005) the goals are as follows:

a. To have every student achieve to his or her potential.

b. To learn how to learn and to think critically.

c. To encourage students to take an active role in their own education by bringing their stories and experiences into the learning scope.

d. To address diverse learning styles.

e. To appreciate the contributions of different groups who have contributed to our knowledge base.

f. To develop positive attitudes about groups of people who are different from ourselves.

g. To become good citizens of the school, the community, the country and the world community.

h. To learn how to evaluate knowledge from different perspectives.

i. To develop an ethnic, national and global identity.

j. To provide decision making skills and critical analysis skills so the students can make better choices in their everyday lives.

Multicultural education is defined as one that allows full development of the potential and critical abilities of all children regardless of their differences (racial, ethnic, gender, class stratification, disabilities, and sexual orientations). Multicultural approach posits that:

$>$ Every student must have an equal opportunity to achieve to her or his full potential.

D Every student must be prepared to competently participate in an increasingly intercultural society.

$>$ Teachers must be prepared to effectively facilitate learning for every individual student, no matter how culturally similar or different from her- or himself.

$>$ Schools must be active participants in ending oppression of all types, first by ending oppression within their own walls, then by producing socially and critically active and aware students.

$>$ Education must become more fully student-centered and inclusive of the voices and experiences of the students.

$>$ Educators, activists, and others must take a more active role in reexamining all educational practices and how they affect the learning of all students: testing methods, teaching approaches, evaluation and assessment, school psychology and counseling, educational materials and textbooks, among others. 
$>$ The selection of subject matter content should be culturally inclusive, based on up-to-date scholarship. This inclusivity should incorporate opposing opinions and divergent interpretations.

$>$ The subject matter content selected for inclusion should represent diversity and unity within and across groups.

$>$ The subject matter selected for inclusion should be set within the context of its time and place.

$>$ The subject matter selected for inclusion should give priority to depth over breadth.

$>$ The subject matter content should be treated as socially constructed and therefore tentative -- as is all knowledge.

$>$ The teaching of all subjects should draw and build on the experience and knowledge that the students bring to the classroom.

$>$ Pedagogy should incorporate a range of interactive modes of teaching and learning in order to foster understanding (rather than rote learning), examination of controversy, and mutual learning.

\section{Implications of Human Right and Multicultural Approaches to Curriculum THEORY AND PRACTICE}

Curriculum can be envisaged from different perspectives. What societies envisage as important teaching and learning constitutes the "intended" curriculum. Oluoch (2006) definescurriculum is all that is planned to enable the students acquire and develop the desired knowledge, skills and attitudes. Curriculum is also seen as total guided learning experiences designed to facilitate learners learning for establishing quality relationship between what is learnt and what operates outside the school. Dike and Eze (2009) observe that curriculum involves the acquisition of skills needed to perform tasks. Curriculum is for the betterment of the society but adequate efforts must be made to ensure that the interests and needs of the learners are not compromised. Curriculum involves a dynamic process and as such must move with the changing trends in the society. Curriculum like education is a product of a wide array of actors (politicians, policy makers, curriculum workers, teachers, laypersons, targeted learners and so on) the implication is that curriculum involves planning at different levels.

Curriculum is for the betterment of the society but adequate efforts must be made to ensure that the interests and needs of the learners are not compromised. Curriculum involves a dynamic process and as such must move with the changing trends in the society. Curriculum like education is a product of a wide array of actors (politicians, policy makers, curriculum workers, teachers, laypersons, targeted learners and so on) the implication is that curriculum involves planning at different levels. The curriculum represents a crucial tool for fostering a broadened concept for inclusive education and to implement educational policy for a long term perspective. A quality Curriculum is critical for operationalization of education and instruction for all learners in an effort to develop relevant competencies that benefit individuals and society at large.

All children should be provided with a curriculum which is relevant to their needs through a range of well planned, shared learning experiences. To promote inclusive education, what is taught in school, how it is delivered, and how resources, both human and material are managed must be decided on collaboratively. It is globally acknowledged that a "one size fit all "curriculum only benefits a minority of learners, leaving many others far behind their social and academic development potential and others with no education at all. There is therefore in the context of quality inclusive a real need to provide shared meaningful learning experiences for students with and without disabilities within the context of classroom activities that address individualized learning needs of each learner (Giangreco and Doyle, 2000).To achieve quality teaching and learning across curriculum for all will require the implementation of inclusive practices. To ensure quality, there is need to shift to student centered curriculum planning based on the assessment of the strengths and weaknesses of the learners, with differentiation in the selection of content and teaching strategies to meet individual learning needs(Smith, 2000). The curriculum must be flexible and responsive to the diverse and complex needs of individual learners. The curriculum should be based on multiple intelligence, Brunner's theory of scaffolding, and social constructivism theories to allow for flexible learning and to create pathways that better address the diverse needs and uniqueness of learners (Hall, Stengman and Meyer, 2009). Learning should be further guided by three main processes of learning: 
a) Recognition of the information to be learned

b) The application of strategies to process the information, and

c) The engagement in learning tasks while giving emphasis to differentiated instruction

(Vyotsky, 1962)

The curriculum must enable every child to acquire the core academic content and basic cognitive skills together with essential life skill that equip children to face life challenges, make well balanced decisions and develop a healthy life style, good social relations, critical thinking and the capacity for non-violent conflict resolution. It must help develop respect for human rights and fundamental freedom, and promote respect for different cultures and value for the natural environments. The curriculum must be inclusive and tailored to the needs of children in different and difficult circumstances. All teaching and learning materials should be free from gender stereotypes and from harmful or negative representations of any ethnic or indigenous group. To enable all children with disabilities to fulfill their potentials, provision must be made to enable them for example to learn braille, orientation or sign language (UNICEF, 2007).

\subsection{Features of an Inclusive Curriculum}

a. It reflects the kind of society to which we aspire in terms of demands and expectations, and define the role of education in society. The curriculum development should be a continuous process closely intertwined with social inclusion.

b. It ensures both equity and quality by effectively responding to learner diversities and sustain education for all in the long term. Long term approach to organization of curriculum should serve as the integrative aspect to link different forms and types of learning.

c. Should address and incorporate national, local and learner diversities.

d. Helps to foster a comprehensive citizenship education.

e. Promote a balance between global, national and local expectations, realities and needs.

f. Reflects diversification of models of instruction and learning materials.

g. Fosters appreciation of diversity and tolerance by incorporating principles of nondiscrimination.

h. Incorporates content relevant to needs and future of learners.

i. Discusses education for sustainable development.

j. Considers and builds on students' prior learning and experiences.

k. Presents learning materials that reflect a diversity of viewpoints and representation.

1. Provides examples and case studies in the subject areas reflecting diversity of knowledge, experiences and cultural values of all the learners.

$\mathrm{m}$. Provides for a wide range of learning opportunities and a variety of learning activities.

n. Presents learning activities that promote interaction, collaboration and shared reflection among the learners.

o. Provides for assessment tasks free of culturally and gender based examples

p. Provides assessment tasks designed to take account of diverse values, goals, experiences and perspectives of learners.

\subsection{Features of an Inclusive Classroom Procedures and Practices}

a) Establishment of classroom routine that is sensitive to individual needs and cultural norms of learners.

b) Ensuring that classroom responsibilities are inclusive and not stereotyped.

c) Provision of instructional resources that reflect diversity of learners.

d) Ensuring that all learners feel accepted and gain a sense of belonging. 
e) Provision to each learner a balance of challenge and support to scaffold new learning.

f) Emphasis and modeling values of fairness acceptance, kindness, respect and responsibility to and for all people.

g) Making education relevant to students' needs and interests.

h) Teaching and modeling independent learning skills.

i) Recognition and value for learner improvement and acknowledging success of each individual learner.

j) Use of evaluation methods that are equitable and take into account the diversity of learner's life experiences and learning needs for example refugee experience.

k) Use of flexible approaches to eliminate barriers and transform learning experiences. Teachers should provide differentiated instruction by acknowledging that students learn at different rates and in different ways (Griffin and Shevlin, 2011).

\subsection{Teachers and Implementation of Inclusive Education}

Teachers are the main in translating education policies into practice through the teaching learning process. The success of the inclusive education therefore depends upon the ability of teachers to respond to diversity in the classroom. The involvement of learners in managing their own learning has a positive effect on learners' self-esteem. Teachers' understanding of teaching and learning style is a major key to the implementation of inclusive education. Classroom practice must take into account how individual students learn most effectively. Teachers with a positive attitude towards inclusion more readily change and adapt the way they work in order to benefit learners with a range of learning needs. Teachers must have appropriate skills and be able to alter the format of the lesson, change arrangement of the group, change the way the instruction is delivered, use different materials and provide alternative tasks (Westwood, 2007). Teachers should provide differentiated instruction by acknowledging that students learn at different rates in different ways(Griffin and Shevlin, 2011).

Teachers have a key role in creating an inclusive learning environment and climate for learning by considering how they can take down barriers to learning to ensure every single learner feels they belong there and are not excluded. A successful inclusive learning environment depends on teachers' open- mindedness; self-awareness and commitment to social justice (Garmon, 2005).Teachers are agents of change and should challenge any assumptions or negative attitudes towards any children or groups. Teacher's role in providing an inclusive learning environment requires establishment of an environment in which every child can participate and feel able to actively engage despite any additional support needs that they may have at any one particular time. This can be achieved through teachers' responses to learners needs by applying flexible approaches, planning and organization. Westwood (2007) asserts that effective inclusion depends on differentiation.

According to Suzanne (2009) teachers can foster independent learning through various ways:

a. Making education relevant to student needs and interests.

b. Using a variety of strategies to gain an understanding of students' abilities, needs and interests.

c. Providing students with choice in assignments and topics within a range of choice.

d. Using collaborative instructional techniques.

e. Teaching and modeling independent learning skills.

Rink (2003) states that teachers in inclusive settings must provide; developmentally appropriate content, clear instruction for practice, opportunities for practice at an appropriate level of difficulty and opportunities to participate in appropriately designed tasks and accurate feedback and assessment of subject matter and role performance.

Teachers are crucial because of the central role they play in promoting participation and reducing underachievement among learners who might be perceived as having difficulties in learning. One of the most cited barriers to inclusion however is the teacher. Several studies (for example by Forlin1998; Hodge et al, 2004; Vaughn et al, 1996) argue that teachers negative attitude could undermine development of inclusion. Without teachers' readiness to accept children with SEN in their 
classrooms, inclusion will not be successful. In addition these studies found that teachers' attitudes were least favourable towards serving children with significant disabilities. Some of the studies concluded that teachers beliefs about inclusion were linked to children individual characteristics and the special needs they exhibited rather than educational placement philosophy.

Corbett (2001) stressed that lack of training and opportunities for professional development are disincentives to inclusion. If teachers do not have the necessary skills to teach children with SEN they might feel frustrated and they cannot accommodated these children in their classes. Studies by (winter, 2006; Reid 2005; and Kristensen et al, 2003) have shown that training, professional development and pedagogy are critical to the success of inclusion programmes. Avramidis and Norwich(2002) contend that without a coherent plan for teacher training in educational needs for children with SEN, attempts to include these children in the main stream would be difficult. It is imperative therefore governments prepare teachers who have both the confidence and the skills to teach in inclusive settings and who are equipped to provide appropriate instruction for all learners.

Another issue related to teachers is the work load; studies have shown that teachers feel they cannot tolerate the overwork load in case of inclusion (Bunch and Finnegan, 2000). This was linked to different barriers like large class size, insufficient time for teachers to cater for needs of children and lack of teachers desire to teach those children. In New Zealand one of the major challenges is that special education ideology is still very dominant in thinking, policy and practice. The special education was built on an ideology of individual pathology that created demarcations between normal and so called abnormal or theories of deficient and on the belief that only expert teachers can understand and meet needs of dialed learners (Ballard, 1990). Corbett and Slee (2000) posit that the theory and practice that forms the special education tradition is essentially compounding the pattern of education and social exclusion witnessed in schools and communities. In contrast inclusive education does not involve itself in norming, labeling and pathologising learners. It involves itself in identifying and minimizing the interactive social-cultural factors that influence the idea of disability and difficulty.

Morton and Gordon (2006) in New Zealand examined the nature and extent of initial teacher education and ongoing professional learning around inclusive education and found how there were problems with how the concept of inclusion is defined and used in the education sector. This affected the way teachers viewed inclusion. A study by Kearney (2007) on disabled who children had been excluded and marginalized from regular school found that teachers demonstrated a lack of responsibility to disabled learners.

With change of education worldwide, education systems are experiencing change in political, economic, social, and technological aspects. This calls for major change to the role of the teachers together with the introduction of new approaches to curriculum, assessment and inclusive education policies. This has necessitated the focus on what the child requires to support his/her learning. Such development has effect on professional identity as well as the roles and responsibilities of teachers. It has implications on how teachers are trained and supported in their professional development. In many teacher education programmes the infused or permeated mode of teacher preparation is adopted. This is a process by which special education needs matters are embedded within subject based parts of teacher training course. The infused mode is criticized for not allowing enough time for the preservice teachers to develop the necessary knowledge, skills and attitudes (Cook, 2002). In Kenya for example, there is currently very little time allocated within initial teacher training programmes to cover issues of inclusion and additional support needs. In some of the universities offering teacher education, special education is offered as an elective unit.

According to Aniscow (2003) teacher development has to be the heart of initiatives for developing inclusive practices in schools. This requires building competencies of all "regular teachers" to deal with diverse population of students and to learn pedagogical strategies that facilitate the learning of all students in the classroom. Quality inclusive education system requires a more acknowledged, highly skilled teaching force. There is need to strengthen knowledge, skill, and attitudes of teachers for creating inclusive ethos and learning environment in schools. Teacher education programmes should equip teachers with:

a) Fundamental competencies which provide knowledge base to teachers for understanding philosophy assumption underpinning inclusive education policies and practices, understand the nature and barrier to learning, learning style among others. 
b) Skills to examine and reassure attitudes towards other cultures.

c) Skills to develop empathy and treat all students as individuals.

d) Skills to promote the success of all students and strategies to deal appropriately with prejudice at school.

e) Skills to work in multicultural settings including understanding of the value of diversity, and respect of differences.

f) Practical competencies which require teachers to develop the skills to perform the action creating a learning environment, undertaking analysis of barriers to learning, developing teaching strategies, developing resources to support learning.

g) Reflective competencies which help teachers to reflect how language, disability, race. Gender, geographical locations and their differences impact on learning and appropriate adaptation to teaching strategies to maximize participation of all learners

h) Skills to work in close collaboration with colleagues, parents and wider community.

i) Skills necessary to help learners acquire the competencies listed in the European Reference Framework of key competencies(communication, mathematical, competencies in science and technology, digital competence, learning to learn, social and civic competencies, sense of initiative and entrepreneurship and competencies in cultural awareness and expression)( European Committee, 2007).

j) Skills to monitor effectiveness of classroom interventions.

Teacher education is therefore seen as a core element for building the capacities of education systems to move toward more inclusive system.

\section{CONCLuSion}

Worldwide in education practice, there is a move to inclusive education policies emanating from the 1948 Universal Declaration of Human Rights. Many treaties, declarations and international conventions commit governments of countries to this. To realize this, a number of approaches have been adopted to promote inclusive education systems. Among them are the Human Rights Based approach and the Multicultural approach which have major implications to curriculum theory and practice in relation to curriculum design, content of curriculum, strategies of instruction, choice of resources, grouping of learners among others. To effectively implement inclusive education, the teacher factor should be taken into consideration as part of teacher development to instill necessary competencies that will support the teaching learning process and promote development of all learners. At the highest level, inclusive education should be seen as a systematic change at all levels; principals, teachers, learners, school communities, policy makers, decision makers, families, and society at large.

\section{REFERENCES}

[1] Grubb,W.N \& Lazerson,M.The education gospel. The economic power of schooling. (Cambridge: Havard University press,2004).(1)

[2] UNESCO The UNESCO Salamanca Statement and Framework for Action on Special Needs Education.(Paris: UNESCO, 1994). (1)

[3] Ball,S.J.(2006). Education policy and social class. ( London: Routledge, 2006.)(2)

[4] Commission for Social Justice . Strategies for national renewal. (London: Vintage, 1994). (2)

[5] Dyson, A. (1999). Inclusion and Inclusions. Theories and discourse in inclusive education. (London: Sage, 1994). (2)

[6] European Agency on Development of Special Needs Education (2006). Inclusive education (2)

[7] Evans, J. \& Lunt, I. (2012). Inclusive education: Are there limits? European Journal of for Learning, 21, (2), 2012, 85-91. ( 2)

[8] Field, S; Kuczera,M.\&Pont,B.No more failures. Ten steps to equality in education.OECD for UDL implementation.(Wakefield, MA: National Center on Assessing the General Curriculum, 2007). (2)

[9] Reay, D.(2014). Socially just education.(Cambridge University: British Education Research Association, 2014).(2) 
[10] Seed . Getting it right for every child. (Edinburg: Seed, 2006) 2

[11] Bailey, J. Inclusion through categorization.(London: Rout ledge, 1998).(3)

[12] Brooth, T. \& Ainscow, M. (2002). The index for inclusion.(UK centre for studies on inclusion education, 2002). 3

[13] Brooth, T. The poverty of inclusive education. (London: Routledge, 1998). (3)

[14] Dyson, A.;Farrel.p;Polat\& huchenson, G. Inclusion and pupils achievement. (University of research Report: Newcastle, 2004). 3

[15] Pijlet (1997). Inclusive education. global agenda.A (London: Routledge, 1997) . (3)

[16] Thomas, G. and Vaughan, M. Inclusive Education - readings and reflections. Madenhead, UK: Open University Press, 2005). (3)

[17] United Nations (1989). UN convention on the Right of the child. New York: Author. 3 UNESCO. (2007). A human Right Based approach to education for all. Framework for the realization of Children's rights to education and rights within education.(New York: UNESCO, 1989). (5)

[18] Bank, J.A.(1998). The lives and values of researchers. Implications for educating citizens in multicultural society. Educational researcher, 4-17. (9)

[19] Banks, J. \& McGee Banks, C. Handbook of research on multicultural education. (New York: Macmillan, 1995). (9)

[20] Phinney, J.S. and Rotheram, M.J. Children's Ethnic Socialization: Pluralism and Development. (Sage Publications: Thousand Oaks, .1987). (9)

[21] Sleeter, C. \& Grant, C. (2008). Making choices for multicultural education: fiveapproaches to race, class, and gender. (New York:John Wiley, 2008). (9)

[22] Hanley, M. S. (2005)."The Scope of Multicultural Education." New Horizons for Learning. http://www.newhorizons.org/strategies/multicultural/hanley.htm (10)

[23] Dike, H. I. \& Eze, R. O. (2009). Designing a Curriculum. Curriculum Theory and Practice. (Curriculum Organization of Nigeria, 2009).(12)

[24] Giangreco, M.F. \&Doyle,M.B.(2000).Curricular and instructional considerations for teaching students with disabilities in general classrooms.(Hillside: Lawrence Eribaum, 2000).(12)

[25] Oluoch G.P.Essentials of curriculum development.(Nairobi: Longhorn, 2006). (12)

[26] Smith, M.K. (2000).Curriculum theory and practice. Special Needs Education, 17(1), 1-14. 12

[27] www.infed.org/biilio/b-curic.htm.

[28] Hall, T. S., N., \& Meyer, Adifferentiated instruction and implications.(Routledge Falmer,2009).(13)

[29] UNICEF. Implementation of the Convention on the Rights of the Child.(UNICEF Innocenti, 2007). ( 13)

[30] Vygotsky, L.SThought and Language.(Cambridge:MIT Press, 1962). (13)

[31] Garmon, M.A. Six key factors for changing pre-service teachers' attitudes/ beliefs about diversity. Education studies, 38(3), 2005, 275-286.(14)

[32] Griffin \& Shevlin Responding to special educational needs.(Dublin: Gill and MaCmillan, 2011). (14)

[33] Westwood, P.(2007). Commonsense methods of children with special needs: strategies for regular classroom. (London: Routledge Flamer, 2007).(14)

[34] Avramidis, E. \& Norwich, B. (2002). Teachers' attitudes towards integration/inclusion: A review of the literature, in European Journal of Special Needs Education, 17,129-147. 15

[35] Bunch,G. \&Fnnegan, K.Values teachers find in inclusive education. Including the excluded.(Manchester: International special education congress classroom practice. http://www.european.agency.org/iecpintro.htm, 2000).(15)

[36] Forlin, C. Teachers' perceptions of the stress associated with inclusive education and theirmethods of coping. Paper presented at the National Conference of the Australian Association of Special Education, Brisbane, 1998). 15

[37] Hodge, S.R., Ammah, J.O.A., Casebolt, K., LaMaster, K., O"Sullivan, M. High school general physical education teachers" behaviors and beliefs associated with inclusion. Sport, Education and Society, 9 (3) 2004, 395-419.

15

[38] Kristensen,K; Omagor, M. \& Onen, N.(2003).The inclusion of learners with barriers to learning and development into ordinary school setting: a challenge for Uganda, 2003). British journal of special education 30 (4), 2003, 194-201.(15)

[39] Reid, G. Learning styles and inclusion.(London:Sage, 2005).15 
[40] Corbett, J. (2001) Supporting Inclusive Education: A Connective Pedagogy. (London: Routledge Falmer, 2001).(15)

[41] Rink,J.K. Teacher quality: understanding effectiveness of teacher attributes. (Washington DC: Economic Policy Institute, 2003). (15)

[42] Suzanne, D. Teaching methods to encourage independent learning and thinking.( United states Military Academy: WestPoint, 2009).(15)

[43] Vaughn, S., Schumm, J. S., Jallad, B., Slusher, J.,\& Samuel, L. (1996). Teachers' views of inclusion.Learning Disabilities Research and Practice, 11(2), 96-106. 13

[44] Winter, E.C. (2006). Preparing new teachers for inclusive schools and classrooms. Support for Learning, 21(2), 85-91. 15

[45] Aniscow, C.Inclusive education practices .(London: Sage, 2003). (16)

[46] Ballard, K. (1990). Special education in New Zealand. International Journal of Disability Development and education, 37(2), 1990, 109-124.(16)

[47] Cook, B. G. Inclusive attitudes, strengths, and weaknesses of pre-service general educators enrolled in a curriculum infusion teacher preparation program. Journal of Teacher Education and Special Education, 25(3) 262-277, 2002.(16)

[48] Corbett, J. \& Slee, R. (2000). An international Conversation on inclusive education.(Londan: David Fuston, 2000).(16)

[49] Kearney, A. (2007). Exclusion at school: What is happening to disabled students? Amsterdam.

[50] Morton, M., \& Gordon, L. Inclusive education in Aotearoa: what are we doing in initial teacher education professional learning and development?( New Zealand: Canterbury University,2006). (16)

[51] European Committee (2007). Review of the 2006 Framework of key competencies for lifelong learning.(European Commission, 2007).(17)

Citation: Mercy M. Mugambi. "Approaches to Inclusive Education and Implications for Curriculum Theory and Practice." International Journal of Humanities Social Sciences and Education (IJHSSE), vol 4, no. 10, 2017, pp. 92-106. doi:http://dx.doi.org/10.20431/2349-0381.0409013.

Copyright: (C) 2017 Authors. This is an open-access article distributed under the terms of the Creative Commons Attribution License, which permits unrestricted use, distribution, and reproduction in any medium, provided the original author and source are credited. 